\title{
Exploring Factors that Influence the Food Behaviors of Junior Enlisted Army Family Members
}

Tandalayo Kidd, PhD, RD, LPN (Corresponding autor)

Extension Specialist/Assistant Professor

Kansas State University

Department of Human Nutrition

203 Justin Hall

Manhattan, KS 66506

martan@ksu.edu

Paula K. Peters

Associate Professor

Kansas State University

Department of Human Nutrition

340 Justin Hall

Manhattan, KS 66506

peters@humec.ksu.edu

Carol Ann Holcomb, PhD, CHES

Professor

Kansas State University

Department of Human Nutrition

210 Justin Hall

Manhattan, KS 66506

carolann@ksu.edu

With the stress of the on-going war and soldiers being deployed, the needs of military families

have likely increased. Young military families, generally E-4s (Specialists) and below, may

suffer even more stress due to lack of experience and life skills. Many families have seen

financial difficulties arise as a result of the soldier being deployed. The nutrition and health

status of these families may be at risk because of some of the dietary behaviors associated with

limited financial resource audiences. Thus, the purpose of this study was to explore factors that influenced the food behaviors of junior enlisted (E-4s and below) Army families.

Key words: low-income families, military families, qualitative research, focus groups, dietary behaviors 


\section{INTRODUCTION}

Military families, like civilian families, suffer when financial resources are low. Food choices and/or diet may be affected by limited financial resources, thus impacting overall health status. Removing slime from lunch meat, removing mold from cheese, removing mold or insects from grains, removing spoiled parts of fruits and vegetables, and diluting beverages are practices Kempson et $\mathrm{al}^{1}$ reported some low-income individuals may use to manage their food supply. These practices increase the risk of food borne illnesses and put the individual at nutritional risk. However, there are other cost-saving techniques used by some low-income families that are not as nutritionally compromising, such as buying generic brand or lower quality products, using coupons, shopping for sale items, buying larger package sizes, ${ }^{2}$ or making low-cost meals. ${ }^{1}$

According to the U.S. Department of Health and Human Services, ${ }^{3}$ the 2004 poverty guidelines for a family of four is an annual gross income of $\$ 18,850$ or gross monthly income of \$1,571. The Department of Defense (DoD) ${ }^{4} 2004$ Military Pay Scale indicated an enlisted soldier with a pay grade of E-4 (Specialist), the highest of the junior enlisted ranks, would receive a base pay of approximately $\$ 1,558$ - $\$ 1,891$ per month, depending on the length of service time. An E-3 (Private First Class), with three or more years in the service, would be living only \$15 per year above poverty level, and the E-2s (Private) and E-1s (Private) would be living below poverty level regardless of time in service, if they had a four-member household.

Other sources of support to these soldiers includes government housing or a tax-free housing allowance to cover rent utilities and other housing expenses. ${ }^{5}$ Although government housing or the housing allowance contribute to the income of military families, generally the value of this additional income would not be sufficient for the families to rise above "lowincome” status. Also, government programs, such as Food Stamps and Special Supplemental 
Nutrition Program for Women, Infants, and Children (WIC) are available to low income households whose annual total income does not exceed $130 \%$ or $185 \%{ }^{6,7}$ respectively, of the federal poverty level.

In addition to having low incomes, expenses to military families have increased in the last few years. While soldiers are deployed to Iraq, families are faced with more financial stress that can be in the form of childcare costs, family support, transportation, emotional support, and more. $^{8-9}$

Military families deal with unique problems that are associated with relocations and deployments. ${ }^{10}$ While low income civilian families also face hardships, spouses of deployed soldiers have the added stresses of separation and worrying about their spouse's safety. ${ }^{9}$ These issues are even more pronounced for families of soldiers who are serving in the military for the first time. Young military families, generally E-4s or below, may suffer more stress due to lack of experience and life skills. ${ }^{11}$ While some spouses may be able to find employment to supplement the household income, many are young with few job skills, thereby limiting the jobs they are qualified to do. For spouses that do find work, the amount of pay may be insufficient to cover added expenses such as childcare or transportation. ${ }^{11}$

Thus, junior enlisted Army soldiers and their families are at high risk of living in poverty. Therefore, the nutrition and health status of these families may also be at risk because of some of the dietary behaviors associated with limited financial resource audiences. Getting people to change a behavior is difficult, but the first step is to understand their needs, perceptions, and wants. Only when these elements are understood can we help people become aware of their need to change. ${ }^{12}$ The purpose of this study was to explore factors that influenced the food behaviors of junior enlisted Army families. 


\section{METHODOLOGY}

\section{Participants}

Approval from the Institutional Review Board (IRB) was received to carry out this study. Participants, living on or near Fort Riley military post, were recruited by word of mouth, flyers posted at a local gas station and the post office, the Armed Forces YMCA, and on-site invitation at a local food bank. Individuals interested in participating in this study were pre-screened in person or over the telephone if they responded to the number listed on the posted flyers. The participants were asked a series of questions from a screener to determine if they met the qualifications for the study. If the individual was married to a junior enlisted soldier and had children living in the home with them, they qualified to participate in the study. If they qualified, they were enrolled in the study and given a date to participate in a focus group discussion. Follow-up post cards were mailed to them soon after enrollment. They also received a reminder phone call one day prior to their focus group session.

\section{Focus Groups Description}

Focus groups allow participants to express their own viewpoints without having to choose from pre-selected answer choices $^{13}$; and questions can be explored to help health professionals understand why participants act and think the way that they do. ${ }^{14}$ Focus groups allow researchers to gain a deeper perspective on issues relevant to the target audience. ${ }^{15}$ The participants in focus groups for this study had the opportunity to discuss issues pertaining to their food behaviors, such as food preparation, food acquisition, traditional foods, food resources and general nutrition knowledge.

Four 90-minute focus groups were conducted over a 2-day period, in the fall of 2004. Participants of two of the focus groups were parents with children five years of age or younger. 
Participants in the other two groups were parents of children six years of age or older. The reason for separating groups by this criterion was an effort to separate possible WIC clients from non-WIC clients. The needs of participants receiving WIC benefits may differ from participants not receiving WIC benefits. If a participant had a child in each of the age groups, the participant was placed in the group with participants of children six years of age and older.

Focus Group Procedure

A focus-group moderator, trained by the RIVA Training Institute ${ }^{16}$, led the discussion groups. A moderator's guide, adapted from Eliades and Suitor, ${ }^{17}$ was designed to elicit information that could be used to help identify the food behaviors of this target audience. The participants were compensated with $\$ 50$ cash for their time, travel, and childcare expenses, since transportation and childcare were not provided.

Signed consent forms were collected from participants at the beginning of each focus group discussion. The researcher served as the assistant moderator and was present to help with consent forms and to take notes during the focus group discussion.

The moderator began each focus group discussion by asking the participants to state their name, number of members in their family, the ages of their children, and the family's favorite food(s). The moderator used an outlined set of questions (Table 1), which led to different probing questions, depending on the responses from the participants. Each participant in all groups was given the same opportunity to respond to a question, although no one had to respond to every single question asked during the focus group discussion.

All focus groups were audio taped and the tapes were transcribed verbatim. The transcriptions were coded manually by assigning a label in the margins of the transcripts for each nutrition issue that appeared. If the nutrition issue appeared again, the same label was assigned 
to that issue. The researcher, the moderator, and an individual with a food safety background coded each transcript independently. To avoid research bias, the categories assigned by each person were compared to identify the commonalities and differences. Differences in categories were reviewed and discussed by the three coders to determine if the category was important enough to stand alone, need to be collapsed into another category, or should be discarded because of its irrelevancy.

\section{RESULTS}

\section{Participants’ Demographics}

Of the 26 respondents recruited for this study, 18 participated in one of the four focus groups that were held over a 2-day period. Group $1(n=2)$ and Group $4(n=6)$ were for participants with children five years of age or younger; and Group $2(n=4)$ and Group $3(n=6)$ were for participants with children six years of age or older.

The majority of the participants $(n=17)$ were females and nearly $28 \%(n=5)$ represented racial and ethnic minorities. Over 30\% $(n=6)$ were between the ages of 18 and 25 and 55.6\% $(n=10)$ were between the ages of 26 and 35. Approximately $72 \%(n=13)$ were spouses of $E-4 s$ (Specialist), nearly 17\% ( $n=3)$ were spouses of E-3s (Private First Class), and 11\% (n=2) were spouses of E-2s (Private). Household size ranged from three to nine members and children ages ranged from $4 \frac{1}{2}$ months to 16 years of age within those households. Thirty-three percent $(n=6)$ received WIC benefits and $11 \%(n=2)$ received food assistance (food stamps) benefits.

\section{Family Eating Habits}

Participants discussed foods commonly eaten in their home and how they are prepared. Participants pointed out that not all members in their family enjoy the same foods; therefore, some participants made special dishes to accommodate a family member's dislikes. Family size, 
family preferences, spouse's deployment, and age of children appeared to influence food choices:

I eat whatever the kids want to cook because my husband is away at NTC [National Training Center]. The kids do all of the cooking when my husband is away. I let them experiment in the kitchen. They cook hotdogs, pre-packaged lasagna, and spaghetti. Whatever they want to cook is what we eat. (Respondent from Group 3)

My children will not eat broccoli without cheese. They are picky. When I prepare spaghetti, I know my son is adamant about not eating spaghetti, so I will fix him something different at that time. (Respondent from Group 2)

There are nine in my family. Rice and ramen noodles are more filling and they both go a long way. (Respondent from Group 2)

Participants indicated factors such as food cost, time, and cooking skills impact the foods eaten in their household. Pasta and chicken were viewed as cheap and easy to prepare; however, participants expressed their family's dislike of having the same thing week after week. Children, in particular, were viewed as difficult when new foods, especially vegetables, were introduced.

\section{Shopping Habits}

Shopping habits of the participants varied from once a day to once a month. Some participants used a grocery list, which they indicated saved them time and money. Sales, coupons, family preferences, and available money influenced purchases. For example: 
My stuff must be on sale. I am the clearance shopper queen. It must be on sale, so that could explain why our meals are a little boring because I buy a lot of the same thing. (Respondent from Group 4)

I don’t buy stuff my family will not absolutely eat, but sale prices determine a lot of what I buy. (Respondent from Group 2)

I don't want to spend more than $\$ 80$ a week on groceries. We are a family of three and if I could stretch that $\$ 80$ dollars to two weeks that would be great. (Respondent from Group 1)

Participants agreed that food was a major factor in their budget. Participants who lived on the military post did not always shop at the military grocery store. Some valued the chain grocery stores because of the variety that they offered and for the business operation hours. Although participants with larger families usually purchased bulk packages of meats and larger canned products, those individuals indicated that the larger sizes did not have an impact on the number of times they would go to the grocery store. Participants who received WIC benefits indicated they usually shopped during the same time that they were redeeming their WIC vouchers:

I am on WIC, so I go [grocery shopping] mainly when I am getting my WIC stuff. I do everything all at once. (Respondent from Group 4)

\section{Cooking Habits}

Few participants used the microwave to cook foods. The microwave was mainly used to re-heat or thaw foods, although some participants admitted to thawing foods at room temperature in a sink. Some participants believed the microwave dried out foods or stripped nutrients from 
foods. Many participants credited their cooking skills to a family member or friend. Participants indicated that they prepared foods similar to what they grew up on and were accustomed to; however, not all spouses accepted their way of cooking. For example:

My husband is from the South and the first few years of our marriage, I would find a plate of food in the garbage that he has thrown away. The biggest problem is the way he was raised in Florida. They eat the same thing we eat, but they just don't add all of the stuff I add to food. He tells me constantly how his mom made food and that's why he doesn’t really eat what I fix. (Respondent from Group 2)

The majority of the participants thought menu planning was a waste of time. Participants believed it was difficult to plan meals in advance because of potential changes in schedules or unforeseen events, unexpected company, and family preferences. However, the few participants who did plan menus believed it saved them time and money at the grocery store, and found it also made it easier for spouses and older children to help with meal preparations.

All participants admitted to owning at least one cookbook, but few indicated that they used it to prepare meals for their families. The majority indicated the cookbooks are used for special occasions or during the holiday season. For example:

I have a lot of recipe books, but I don’t look at them very much. I use mine for like Thanksgiving when you want to do something different. (Respondent from Group 1)

\section{Managing Resources}

The participants indicated a variety of ways in which they manage when financial resources are limited. Some participants stocked up on ramen noodles so that they would have something to eat if they ran short on cash. Some have used one of the local food pantries where they received: 
... powdered milk, dry potatoes, pudding, cereal, oatmeal, canned vegetables, and some

fruit. You can go there once a month. (Respondent from Group 3)

Participants who lived on the military post indicated that they had gotten together with other families for a neighborhood cookout to help stretch the food dollar. WIC benefits were viewed as a means to extending the family's food dollar because of the items that were allowed, such as cheese, beans, cereal, eggs, milk, peanut butter, juice, carrots, and tuna. Some participants relied on family members to help out when finances were low. The military also provides services to assist soldiers and their families with food, although some participants believed that it was difficult to take advantage of those services. For example:

... you can get an advance pay and when [the soldier's] check comes, they will just take it out of that. (Respondent from Group 1)

If you go through the chain of command, they will refer you to the finance officer, which will go shopping with you to make sure that you do not buy the chips. They will make sure that you only get the fruits, vegetables, and needed items to get by on. (Respondent from Group 4)

The military has an excess funding plan. Your husband can receive food assistance, but I have not met one single person who qualified for that, but they did qualify for assistance from the food pantry. Everyone I know who have applied for food assistance from the military was told that they make too much money. I found out about the food assistance by going on the computer. I applied for it, but I was told my husband who is an E-2 with a family of four, makes too much money. (Respondent from Group 3) 


\section{Nutrition Information}

Participants received their nutrition education information from taking college classes, the Internet, grocery stores, food labels, family members, the Army Community Services, and WIC. However, food labels and the grocery stores’ nutrition information appeared to be confusing to participants. For example:

You go to Wal-Mart and see you that you should have 9 fruits and vegetables a day. How can you get 9 different fruits and vegetables a day? Some of it I find impossible. (Respondent from Group 1)

Healthy living and eating habits came to mind when the participants said they thought of nutrition education. Some participants believed the grocery stores should educate the public because they are the ones selling the food items; other participants thought individual counseling with a dietitian or handouts on specific topics would be the best way to learn about nutrition. Classes related to general nutrition and cooking, cooking on a budget, menu planning, cooking with recipes, and healthy, inexpensive snacks for children appeared to be of interest to the participants:

I think something involving kids. My child is small, but more classes on nutrition for small children. They are picky eaters. (Respondent from Group 4)

It's a lot of military families out there and if someone could come out and have a lecture on nutrition. The kids should be invited so that we could all learn together on how to do certain things. Some people in low-income families, we don't know how to budget. Some of us can't afford to go to school and learn. Three dollars may be expensive to someone else. Maybe if we had someone to come out and say that we are going to teach 
you how to eat right and prepare different meals for your family, so that you can

encourage them to eat vegetables. Someone could come out in the community to show us and to teach us. All of us don’t have computers. (Respondent from Group 1)

\section{DISCUSSION}

Many young enlisted soldiers with families are living at or below the poverty level. Among those participating in this study, some participants benefited from services such as WIC and Food Stamps. However, lack of time, difficulty with menu planning, stretching the food dollar, shopping habits, and cooking skills were barriers reported by the participants that could impact the family's food behaviors.

There are several strategies that could be used to manage a family's food supply. As mentioned in the introduction, some strategies such as removing slime from lunch meat, or diluting beverages, ${ }^{1}$ increase the risk of food borne illnesses or put an individual at nutritional risk. However, the participants in this study used several techniques that mirrored cost-saving techniques used by other low-income families that were not nutritionally compromising including using coupons, shopping for sale items, or buying larger package size products. ${ }^{2}$

Menu planning was something not favored by most of the participants because of the belief that it was a waste of time or too difficult. However, menu planning could reduce the amount of money spent on groceries and increase the consumption of healthier food choices, if an individual plans the menus based on major food groups such as breads/cereals, fruits, vegetables, meat or meat substitutes, and dairy products. The few participants who planned their menus saw the benefit of saving time and money at the grocery store, while providing opportunties for older children and spouses to participate in meal preparations. 
Some participants believed their meals were boring to their family members. People like different things; therefore, sensory factors such as flavor, taste, texture, color, form, temperature and method of preparation should not be overlooked when preparing foods. ${ }^{18}$ Family preferences may be different and should be included, when possible, into the menus to give all members of the family a sense of ownership concerning the food they eat.

Shopping lists can be developed from planned menus and could possibly decrease impulse buying. Participants who used a shopping list indicated they saved time and money in the grocery store. Shopping lists can also save trips to the grocery store, which could cut down on automobile fuel cost as well as impulse buying. Individuals who shop with a list can plan for healthier food items, include family members’ preferences, and decrease the chance of buying items they do not need.

The cost of food was a concern. While none of the participants mentioned comparing food prices as a way to cut costs, some indicated that they bought bulk size products. Others bought products on sale to stretch the food dollar.

Participants did not reveal every step they took when preparing meals for the family; however, some food safety concerns arose because some participants were thawing meat at room temperature in their sinks. Additionally, some participants did not know the correct serving sizes of fruits and vegetables and could not accurately estimate amounts eaten.

\section{IMPLICATIONS FOR RESEARCH AND PRACTICES}

The findings from this study revealed there are several elements that are impacting the food behaviors of junior enlisted Army family members. The primary concern appears to center around expanding the food dollar. Classes pertaining to menu planning and shopping on a budget, and extending staple items may help with lowering food bill cost. Education on cooking 
methods, quick and easy recipes, portion and serving sizes, and food safety classes would be beneficial for adding variety into the family’s meals in a healthful manner.

The information from this study will be used to develop a survey questionnaire. The questionnaire will be designed to capture and quantify the food behaviors of a larger segment of the population. Just as other consumers, low income enlisted Army families have a general knowledge about nutrition that they have obtained from various sources including the Internet, television, radio, magazines, and newspapers. ${ }^{19}$ However, nutrition professionals are still responsible for presenting accurate information ${ }^{19,20}$ in a motivating way that will grab the attention of their audience. ${ }^{20}$ The results from this study and the follow-up questionnaire will help address needs that are real and unique to the low income enlisted Army families 


\section{REFERENCES}

1. Kempson KM, Keenan DP, Sadani PS, Ridlen S, Rosato NC. Food management practices used by people with limited resources to maintain food sufficiency as reported by nutrition educators. J Am Diet Assoc. 2002;102:1795-1799. doi:10.1016/S00028223(02)90385-8

2. Kaufman PR, MacDonald JM, Lutz SM, Smallwood DM. Do the poor pay more for food? Item selection and price differences affect low-income household food costs. Washington, DC: Food and Rural Economics Division, Economic Research Service, US Dept of Agriculture; 1997. Agricultural Economic Report No 759.

3. Department of Health and Human Services. Annual update of the HHS poverty guidelines. Available at: http://aspe.hhs.gov/poverty/04fedreg.pdf. Accessed July 22, 2004.

4. Office of the Under Secretary of Defense for Personnel and Readiness. Military Pay and Benefits Website. Available at: http://www.dod.mil/militarypay/pay/by/paytables/Jan2004.html. Accessed July 22, 2004.

5. Department of Defense. Basic allowance for housing website. Available at: https://secureapp2.hqda.pentagon.mil/perdiem/bahintro.html. Accessed January 26, 2005.

6. Food and Nutrition Service, US Department of Agriculture. Food stamp program: Who is the food stamp program for? Available at: http://www.fns.usda.gov/fsp/faqs.htm Accessed July 22, 2004. 
7. Food and Nutrition Service, US Department of Agriculture. WIC eligibility requirements. Available at: http://www.fns.usda.gov/wic/howtoapply/eligibilityrequirements.htm. Accessed August 5, 2003.

8. Rosen LN, Durand DB, Martin JA. Wartime stress and family adaptation. In: Martin JA, Rosen LN, Sparacino LR, eds. The military family: A practical guide for human service providers. Westport, Conn: Praeger; 2000:chap 8.

9. Bell DB, Schumm WR. Providing family support during military deployments. In: Martin JA, Rosen LN, Sparacino LR, eds. The military family: A practical guide for human service providers. Westport, Conn: Praeger; 2000:chap 9.

10. Drummet AR, Coleman M, Cable S. Military families under stress: Implications for family life education. Family Relations. 2003;52:279-287. doi:10.1111/j.17413729.2003.00279.x

11. Wolpert DS, Martin JA, Dougherty LM, Rudin BJ, Kerner-Hoeg S. The special case of the young enlisted family. In: Martin JA, Rosen LN, Sparacino LR, eds. The military family: A practical guide for human service providers. Westport, Conn: Praeger; 2000:43-53.

12. Economos CD, Brownson RC, DeAnglis MA, Novelli P, Foerster SB, Foreman CT, Gregson J, Kumanyika SK, Pate RR. What lessons have been learned from other attempts to guide social change? Nutr Rev. 2001;59:S40-S56.

13. Shepherd SK, Sims LS, Cronin FJ, Shaw A, Davis CA. Use of focus groups to explore consumers' preferences for content and graphic design of nutrition publications. $\mathrm{J} A m$ Diet Assoc. 1989;89:1612-1614. . 
14. Borra ST, Robert E. The art and science of health promotion: Using focus groups to create diet and health messages that consumers will believe. Nutrition Today. 2000;35:47-52.

15. Rice PL, Ezzy D. Focus groups. In: Qualitative research methods: A health focus. Oxford, NY: Oxford University Press; 2001:71-94.

16. RIVA Training Institute. Available at http://www.rivainc.com/RIVA-ModeratorTraining/about_training.htm. Accessed September 6, 2005.

17. Eliades DC, Suitor CW. Celebrating diversity: Approaching families through their food. Arlington, VA: National Center for Education in Maternal and Child Health; 1994.

18. Resurreccion AVA. Sensory test methods. In: Consumer sensory testing for product development. Gaithersburg, Md: Aspen Publishers, Inc; 1998:9-42.

19. Broihier K. Communicating nutrition research to the public: The dietitian's role. Top Clin Nutr. 2000;15:1-9.

20. Rippe JM. Communications 101: Challenges and opportunities of communicating nutrition in the information age. Nutrition Today. 2000;35:196-198. 
Table 1. Questions for focus group discussions.

1. How many people are in your family and what is your favorite food?

Probe: How often do you have your favorite food? Where do you have your favorite food? Do you make your favorite food at home?

2. What types of foods do you consume for meals at home?

3. Tell me generally when you prepare food at home, how would you describe your preparation?

Probe: How long does it normally take you to prepare a meal for your family? What 3 problems do you deal with in preparing a meal for your family?

4. How often do you cook for your family?

5. How do you feel about preparing meals for your family?

6. What are some things that you would consider when you are going to feed your family? Probe: How do you address these issues?

7. Which meal of the day is prepared most often in your family?

8. What specific food items are consumed in your home?

9. Where do you purchase the food items that are consumed in your home? Probe: How do you get to the location where you purchase the food items consumed in your home? How often do you go to ?

10. How do you determine what food items to purchase when you go shopping?

11. Now let's imagine that it is the end of the month, and you are running low on food and you are short on cash because pay day isn't for another 10 days. What options are available for you for food in a situation such as this?

Probe: How did you know about this option? 
12. What comes to mind when you hear someone mention nutrition education?

13. Where or whom do you get your nutrition information from?

14. What are some things that would encourage you to use nutrition education information? 